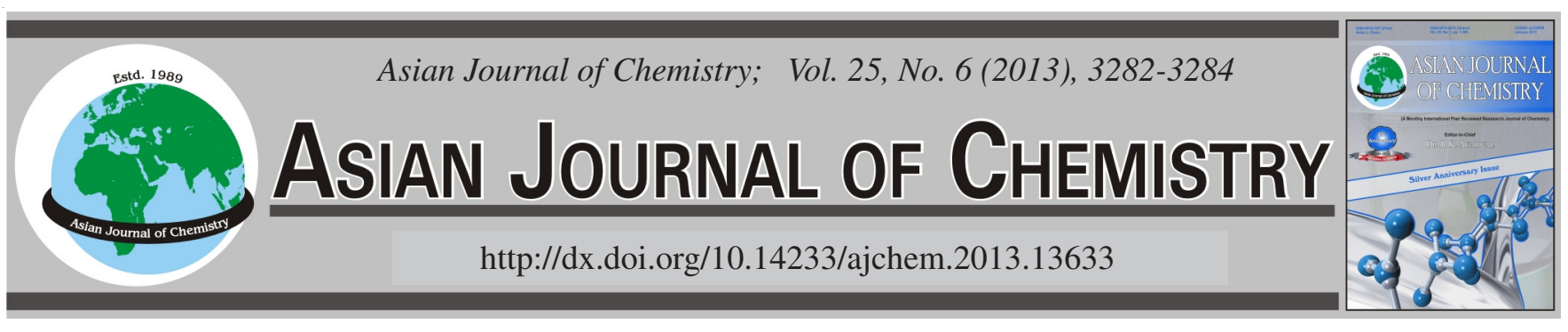

\title{
Determination of Olprinone and Related Materials by RP-LC
}

\author{
Zhiwei Li ${ }^{1, *}$, YUNChaO ZHAO ${ }^{1}$, ERdong LiU ${ }^{2}$ and JiANMin QI ${ }^{1}$
}

${ }^{1}$ College of Chemical \& Pharmaceutical Engineering, Hebei University of Science and Technology, Shijiazhuang 050018, P.R. China ${ }^{2}$ College of Chemistry and Chemical Engineering, Qufu Normal University, Qufu 273165, Shandong, P.R. China

*Corresponding author: Tel: +86 311 88632202; E-mail: lizhiwei@ @ebust.edu.cn

\section{INTRODUCTION}

With the development of aging society, heart failure incidence increased year by year, heart failure has become one of the major diseases leading to death. Heart failure is end stage of coronary heart disease, high blood pressure, the prognosis is even worse than the cancer. There will be life-threatening at any time. statistics show that mortality in patients with severe heart failure up to $50 \%$ after 2 years ill heart failure patients as high as $30-40 \%$ mortality rate, up to $70 \%$ after 6 years.

Olprinone hydrochloride [1,2-dihydro-5-imidazo(1,2alpha)pyridin-6-yl-6-methyl-2-oxonicotinonitrile] (Fig. 1) is an inhibitor of cyclic nucleotide phosphodiesterase III with positive inotropic and vasodilator effects ${ }^{1}$, mainly by inhibiting phosphodiesterase, increase the myocardial intracellular cyclic adenosine monophosphate (CAMP) concentration and intracellular calcium, enhance myocardial contractility.<smiles>Cc1[nH]c(=O)c(C#N)cc1-c1ccc2nccn2c1</smiles>

Fig. 1. Structure of olprinone

The drug has been widely used to obtain good clinical results in Japan and other countries, clinical research data indicate that the goods in terms of efficacy and safety are better than the previous phosphodiesterase inhibitor III. Olprinone is a potent PDE3A inhibitor, would be suitable for protecting against perioperative spasm during coronary artery bypass graft surgery ${ }^{2}$. At the same time olprinone has antiinflammatory effects and inhibits the activation of macrophages, in addition to its inotropic and vasodilatory effects ${ }^{3}$.

The drug was first manufactured and marketed in Japan in 1996, the sales of this product in 1998 was 600 million yen and reached 30 billion yen in 2003. At present, the olprinone has not been imported in China. Therefore, the development of this product will give patients more opportunities for rehabilitation.

\section{EXPERIMENTAL}

HPLC-grade methanol (> $99.9 \%$; v/v) was from Tedia (USA). Potassium dihydrogen phosphate was from Rgent (tianjin, China). All solutions were filtered through $0.45 \mu \mathrm{m}$ PTFE membrane filters prior to HPLC separations. The $\mathrm{pH}$ value was measured using Leici-3c $\mathrm{pH}$ meter.

Precision weighing the olprinone, diluted with water into a solution, which concentration is $1 \mathrm{mg} / \mathrm{mL}$, as the test solution. Precise amount of the test solution 1-100 mL volumetric flask, diluted with water to the mark, as the control solution.

Equipment: The Shimadzu Solution HPLC system used consists of a computer-controlled system with the upgraded Solution software and a CBM-20A System controller. Other accessories were a Shimadzu DGU-20A Degasser, two 
LC-20AD Shimadzu liquid chromatography Pumps, a SIL20A Auto Injector, a CTO-20ACColumn Oven and a SPDM20A Diode Array Detector.

Condition: An Agela Venusil ASB $\mathrm{C}_{18}$ reversed phase column $(4.6 \mathrm{~mm} \mathrm{ID} \times 25 \mathrm{~cm}, 5 \mu \mathrm{m}$ particle size $)$ with a flow rate of $1.0 \mathrm{~mL} / \mathrm{min}$ at $215 \mathrm{~nm}$ was used. Themobile phase consisting of $0.01 \mathrm{~mol} / \mathrm{L}$ dipotassium hydrogen phosphate and methanol in the ratio of $92: 8$ (adjust $\mathrm{pH}=2.5$ with phosphoric acid). An auto injector was used to inject $10 \mu \mathrm{L}$ of the test solution into the HPLC system.

\section{RESULTS AND DISCUSSION}

Selection of analytical conditions: Firstly, we tried to use different kinds of buffer solution such as phosphate, phosphatetriethylamine, by comparison we found that the separation effect of dipotassium hydrogen phosphate and methanol was proved to be better. Follow-up work is to chose the ratio. The more the methanol is, the shorter retention time they are, olprinone and 4 intermediates could not been separated. When reducing the proportion of methanol, the retention time is very long. Finally, dipotassium hydrogen phosphate and methanol in the ratio of $92: 8$ was chosen. And then it was necessary to optimize the phosphate buffer concentration and $\mathrm{pH}$. The concentration of phosphate buffer can influence resolution. A series of concentrations of phosphate buffer were tested. The result showed that at higher concentration,the pressure is high and separation of peaks is poor. Finally, $0.01 \mathrm{~mol} / \mathrm{L}$ phosphate buffer was chosen. Also, the phosphate buffer systems with different $\mathrm{pH}$ values were tested, from 2.5-7.5. It was found that $\mathrm{pH}$ impact on the retention time of olprinone and 4 known species of impurities. Furthermore, the lower $\mathrm{pH}$ value is harmful for column. So we selected the buffer $\mathrm{pH}$ value of 2.5.<smiles>Brc1ccc2nccn2c1</smiles>

1<smiles>CCCCN(C)C=C(C(C)=O)c1ccc2nccn2c1</smiles>

Fig. 2. Structure of 4 intermediates

Fig. 3 is the chromatogram of olprinone, adding 4 known species of impurities to the sample solution. They are 4 intermediates generate during the synthesis (Fig. 2). As shown, the peak of impurities which did not interfere with the peak of olprinone, they are separated completely (resolution $>2$ ).

Follow-up work is to validate its methodology and results are as follows.

\section{System suitability test}

Linearity: Standard solutions of a series of different concentrations of sample were prepared: Olprinone in concentrations of $40,80,100,120,160$ and $200 \mu \mathrm{g} / \mathrm{mL}$. A concentration

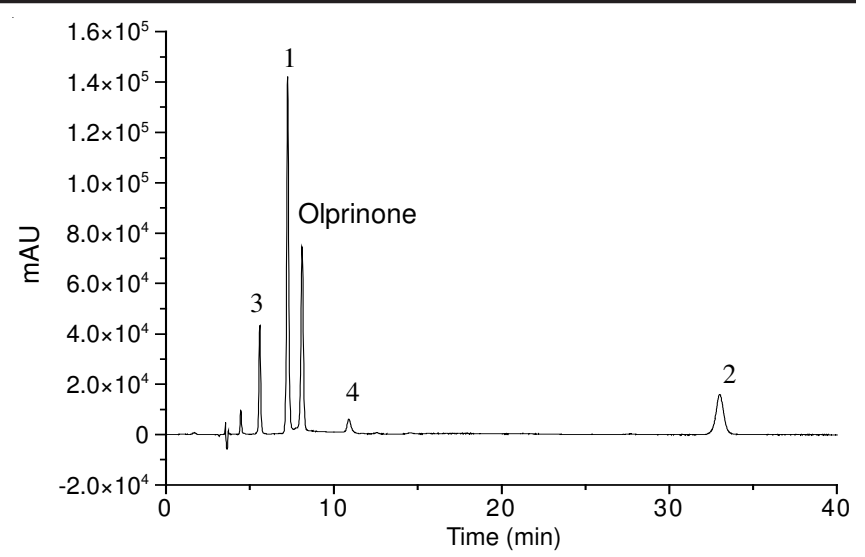

Fig. 3. Chromatogram of olprinone and 4 impurities

as abscissa and peak area for the vertical coordinates of the linear regression. The regression equation is $\mathrm{Y}=37815 \mathrm{X}$ 17637, the correlation factor $(r)$ is $0.9993(n=6)$. Standard curve shown in Fig. 4.

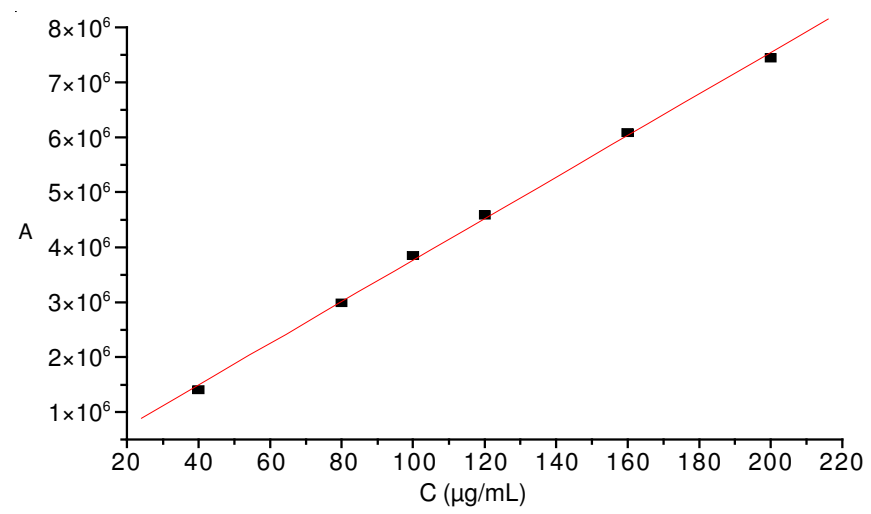

Fig. 4. Standard curves of olprinone

Precision: Replicated analyses of standard solution were performed at the same condition. The values of peak area obtained ws used for calculation of the relative standard deviation.

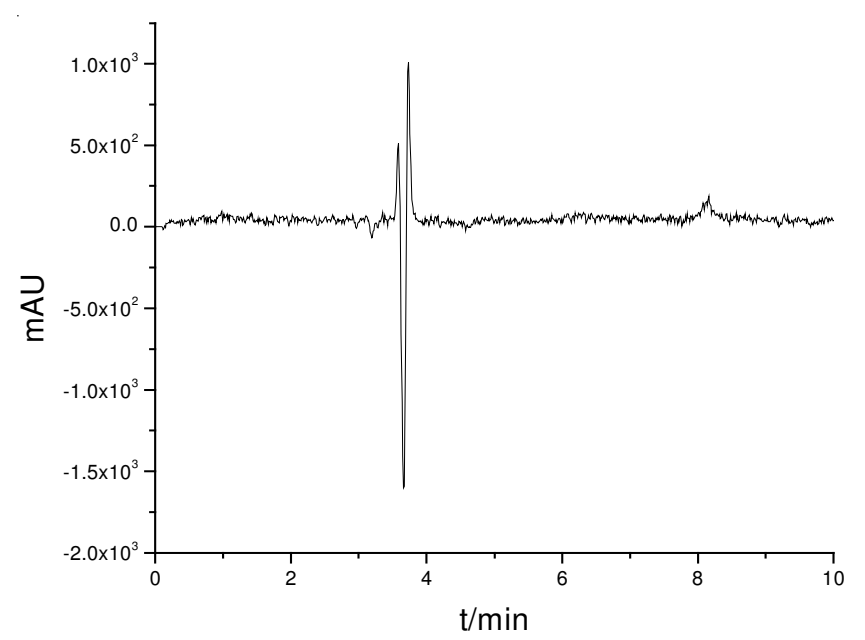

Fig. 5. LOD

In these experimental conditions, the $100 \mu \mathrm{g} / \mathrm{mL}$ of olprinone repeated injection of sample solution 6 times to study the precision of this method, the results shown in Table-1. 


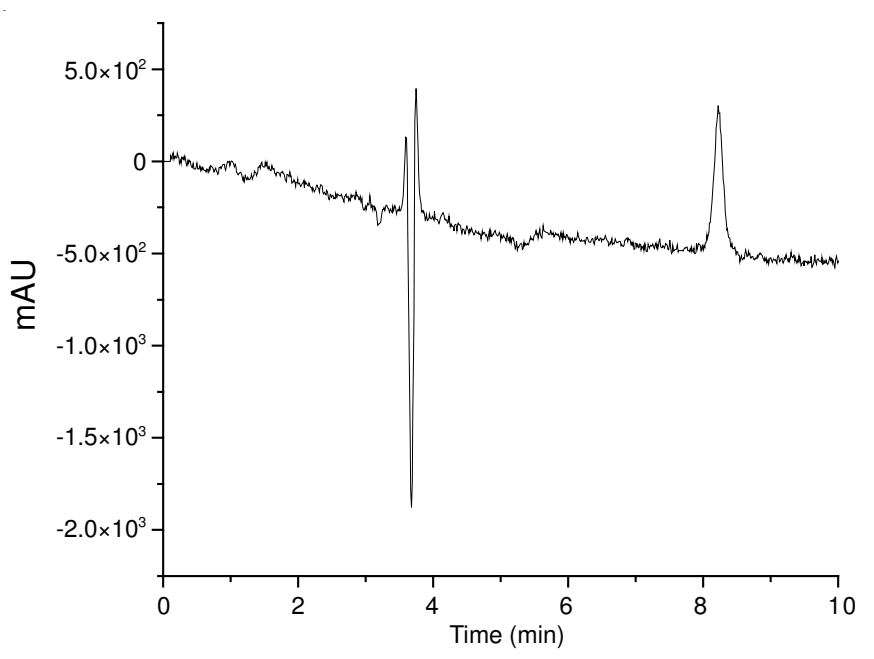

Fig. 6. LOQ

\begin{tabular}{cccc}
\multicolumn{4}{c}{ TABLE-1 } \\
& \multicolumn{2}{c}{ PRECISION OF OLPRINONE (RSD: } & \\
& RELATIVE SANDARD DEVIATION) & \\
\cline { 1 - 2 } & Area & Average & \\
\hline 1 & 4203163 & & \\
2 & 4195861 & & 0.095 \\
3 & 4201476 & 4199912.17 & \\
4 & 4197189 & & \\
5 & 4205422 & & \\
6 & 4196362 & & \\
\hline
\end{tabular}

Recovery: The accuracy of this method was assessed by the determination of mean recoveries at different limits of quantitation, mid range and $80 \%$ of the highest standard in triplicate. Olprinone were prepared into 80, 100 and $120 \mu \mathrm{g} /$ $\mathrm{mL}$ of the solution accurately weighed. The ranges of recovery were 98.65-101.29\% and the results of standard addition recovery studies shown in Table- 2 .

TABLE-2

RESULTS OF RECOVERY REPORTED BY THE HPLC

\begin{tabular}{cccccc}
\hline & $\begin{array}{c}\text { Add } \\
(\mu \mathrm{g} / \mathrm{mL})\end{array}$ & $\begin{array}{c}\text { Detect } \\
(\mu \mathrm{g} / \mathrm{mL})\end{array}$ & $\begin{array}{c}\text { Recovery } \\
(\%)\end{array}$ & $\begin{array}{c}\text { Average } \\
(\%)\end{array}$ & $\begin{array}{c}\text { RSD } \\
(\%)\end{array}$ \\
\hline \multirow{3}{*}{$80 \%$} & 77.42 & 78.42 & 101.29 & & \\
& 76.86 & 76.23 & 99.18 & & \\
\cline { 1 - 4 } $100 \%$ & 77.61 & 76.56 & 98.65 & & \multirow{2}{*}{0.82} \\
& 95.30 & 94.95 & 99.64 & & \\
\cline { 1 - 3 } $120 \%$ & 95.05 & 94.87 & 98.77 & 99.56 & \\
& 114.77 & 114.15 & 99.46 & & \\
& 113.64 & 112.89 & 99.34 & & \\
\hline
\end{tabular}

Limit of detection and limit of quantification: LOD (limit of detection) is defined as the concentration that generates signal equivalent to three times noise $(\mathrm{S} / \mathrm{N}=3)$ (Fig. 5) and LOQ (limit of quantitation) is defined as the concentration that generates signal equivalent to ten times noise $(\mathrm{S} / \mathrm{N}=10)$ (Fig. 6). They were calculated and found as 0.1 and $0.3 \mathrm{ng}$, respectively.

\section{Conclusion}

Through the exploration of chromatographic conditions, we found that concentration and proportion of buffer, $\mathrm{pH}$ value have a great impact for the peak. Ultimately determine the ideal conditions for olprinone and 4 kinds of impurities completely separated: $\mathrm{C}_{18}$ reversed phase column with a flow rate of $1.0 \mathrm{~mL} / \mathrm{min}$ at $215 \mathrm{~nm}$ was used. The mobile phase consisting of $0.01 \mathrm{~mol} / \mathrm{L}$ dipotassium hydrogen phosphate and methanol in the ratio of 92:8 $(\mathrm{pH}=2.5)$. The calibration curve for olprinone was linear in the concentration range of 40-200 $\mu \mathrm{g} /$ $\mathrm{mL}$. The average recovery was $99.56 \%$ with RSD of $0.83 \%$. A rapid, simple, efficient and cheap method has been developed for the determination of olprinone and 4 impurities by using high performance liquid chromatography method.

\section{ACKNOWLEDGEMENTS}

This work was supported by Ideal \& Hightech Pharmaceutical Co. Ltd.

\section{REFERENCES}

1. D. Rosanna, M. Emanuela, P. Irene, I. Daniela, B. Placido and C. Salvatore, Eur. J. Pharmacol., 650, 612 (2011).

2. A. Hideyuki, K. Motoharu and K. Yoshihiko, Eur. J. Pharmacol., 528, 137 (2005).

3. K.. Terumoto, N. Muhammad, T. Masanori, T. Masaru, S. Masayuki and H. Junichi, Pulmonary Pharmacol. Therapeut., 21, 166 (2008). 